\title{
The Engineering Space Workforce of Tomorrow The Integrated Space Engineer
}

\author{
Jens F. Dalsgaard Nielsen * and Dan D. V. Bhanderi *
}

\begin{abstract}
The space engineer of tomorrow needs a variety of skills ranging from high specialized knowledge to cooperative capacities and the ability to understand and even to a certain degree to be productive outside their specialized skills.

Newly educated engineers often lack many of these skills due to the nature of their education. It normally takes five years to become a M.Sc. At many universities these five years comprise mostly of lectures and small projects with no obligation for a success in regards to the final product or prototype.

At Aalborg University(AAU) this is overcome by enhancement of the curriculum by combining Problem/Project Based Learning with actual design and construction of student nano satellites.
\end{abstract}

\section{Introduction}

Satellites and space crafts are nowadays more complex than ever and carry many very expensive and complicated payloads or even human beings. At the same time development and construction time need to be minimized due to economics and requested time of delivery. Although it is very dangerous to generalize but in general an engineer needs an understanding of the common goal and shall have skills for developing highly integrated solutions at small scale (sub- or sub-subsystems) and at larger scale.

To become an efficient space engineer many skills not normally achievable at the curriculum of the universities are needed:

- skills for working efficient in teams

- skills for working "outside" own area of profession

- skills for working with people with other educational background

- to take responsibility

- to be able to obtain new skills when needed

- to be a sustainable workforce even in critical situations

Newly educated engineers often lack many of these skills due the nature of their education. It normally takes five years to become a M.Sc. At many universities these five years comprise mostly of lectures and small projects with no obligation for a success in regards to the final product or prototype.

This paper deals with the way these skills are obtained within the normal curriculum at AAU.

\section{The AAU PBL Model}

At AAU these problems are traditionally partly addressed in the normal curriculum. AAU has a long tradition for Problem and Project Based Learning(PBL) at all three faculties since the birth of the University in $1974,{ }^{1},{ }^{2} .3$

The PBL paradigm is the cornerstone in education of engineers at AAU. The students are given an increased responsibility for their own learning, as individuals and to some extent on group level, by working in

*Associate Professors, Department of Electronic Systems, Section of Automation and Control 
project groups. This requires the students to cooperate in carrying out the project work and communicate the curriculum between them. This teaching method yields higher level of reflection and deeper understanding $[1,2]$ and at the same time promotes learning to "work like an engineer".

The typical duration for a student project is one semester (five months). In that time the students shall comprehend new knowledge (curriculum) for that semester and at the same time carry out a project. A typical student working group consists of 3-7 students and have their own private office at the university. They have $24 / 7 / 365$ admittance to their office and to the laboratories.



Figure 1. Activities in PBL.

The outcome of a typically student project will be a high quality report describing the project including problem definition, analysis, pre-design, detailed design: in addition to that a tested implementation of a prototype are produced by the students. At master level many of the projects are in close cooperation with the industry that formulates problems they would like to have addressed and analyzed.An additional benefit is the access to new work force. It shall be mentioned that $50 \%$ of their time is used for "traditional" lectures and exercises and $50 \%$ for carrying out the project.

The AAU education system has over the years proved to be very rewarding for the graduates, and it is very popular amongst the students themselves, who prefer real-life engineering problems compared to hypothetical, academic problems and lectures. This has also lead to a highly beneficial cooperation with the local industry as many student projects are proposed by companies. AAU students are of course examined within the same set of rules as other master educations in Denmark. Our rating is at least as high as others. $75 \%$ of the master students graduate after 5.2 year (nominal M.Sc. study is 5 years) compared to $25 \%$ for a competing Danish university. At international level the AAU model are adapted around the world.

\section{II.A. PBL and space}

The AAU PBL model does not guarantee that the skills needed for space engineers are achieved because of the built in limits in the normal PBL model: ${ }^{4}$

Within the engineering education, skills are obtained by a combination of traditional lectures and group based project work with guidance and supervision from scientific staff.

In the figure below is shown at traditional PBL project activities for fulfillment of the goal:

- Projects normally last one semester (five month).

- Projects are carried out within the scope of their specialization (control engineer, telecom engineer,...) with no interactions between specializations.

- 4-7 people in a project group and five months duration sets natural limitations on the size and complexity of the project

- After a five month project some work still remain to reach a mature quality to launched up in space.

For a detailed description of the AAU implementation of the PBL model see [3, 4] or visit http://www.puc.aau.dk.

In this paper we present an extension to the traditional PBL model, named Large Scale PBL, which has been implemented in a number of student satellite projects. 


\section{Satellite Construction as a Driving Factor}

Spacecraft activities at AAU has it origin in the first Danish satellite Oersted, with primarily responsibility for ADCS construction. This success lead to start up of building student satellites in 2001 inspired by Prof Twiggs from Stanford University - without him and his help no student satellite activities at AAU. To summarize our past and present space activities at student level are:

- Building our own student CubeSat named AAU Cubesat from 2001-2003. Launch was successfully and some month of partial operation was achieved. Payload a camera.

- Construction of several gravity less objects which has been tested on ESA zero-G flights. The most successfull was Microgravity Isolation using Electro-Magnetic Actuators (Miema) which was re invited for a pro zero-G flight.

- Building our second cubesat AAUSAT-II which are just finalized and will be launched ultimo 2007. Payload: gamma radiation detector and magno torquer/momentum wheel ADCS.

- Just started on AAUSAT3(autumn 2007). Launch ultimo 2009. Payload AIS receiver for monitoring ships in polar regions - especially around Greenland.

- ESA Education SSETI EXPRESS Satellite(launched October 2005) AAU responsible for 4 subsystems and Mission Control Center an Ground Stations.

- GENSO Global Ground Station. (ESA,NASA,JAXA,CSA educational activities)

Despite our relatively small size it has been possible to engage about 25-50 students a year within our student space activities. In the beginning our main focus was naturally on satellite construction but after AAU cubesat it was realized that our way of problem and project based education was well suited for an extension for educating space engineers.

\section{III.A. Our educational Goals}

This naturally what has become our four primary goals - please note that the actual construction of spacecrafts is only one out of five.

1. To educate and launch the space engineer of tomorrow

2. To develop and build spacecrafts and space components and experiments.

3. To do it ourself and in cooperation with other educational sites

4. To exchange "space" students with other institutions

5. To produce a prime quality product. Engineers.

\section{The "PBL" Plan}

To have as much as possible integration with the 2 semester a year educational curriculum the following structure is an outcome of AAUSAT-II (and will be used on AAUSAT3)(each one semester). It is regarded as important that students have the possibility to participate from birth to launch within their stay at the university. The phases are: (see http://www.aausat3.space.aau.dk for our next plan).

- Pre-selection of payload(s)/experiment(s)

- Pre-phase A: Pre-phase study and User Req Specification

- Phase A/B, Design phase and detailed interface, system and budgets

- Detailed design: Approved Engineering model construction

- Integration and test: Integration and Test of flight model 
The duration of these activities are planned to last four to five semesters in total, including pre-selection of payload/experiment. This makes it possible to design, construct and build a satellite within 2-2.5 year.(which has been proved by SSETI EXPRESS (which tool 16 month to design and build with students from all over Europe).

To be able to fulfill the goal "to build a satellite" it is necessary to have students from different educational specializations to work closely together:

- Mechanical engineers: the physical structure

- Telecom engineers: radio link (satellite and ground segment)

- Automation and Control: attitude control

- Computer engineers: digital electronics on-board computer

- Power engineers: on-board power supply

- System engineering and Management: ALL

AAUSAT-II has been constructed by more than 80 students from four Departments at AAU. This diversity in educational curriculum demands special skills from the students to get things to work. It also sets some demands on the educational specializations because this is not daily educational "business". Students, as well as teachers, have to team up to make this a success. For that reason all students get the same curriculum in system engineering and additional space technology and system engineering courses or activities. In this way it has been proved that new specialization can be based and to a certain extent integrated in a standard curriculum.

\section{IV.A. Invisible Management}

In searching for new and more efficient ways of running a complex operation it was decided to let the students take over management - and having faculty staff as "invisible" members of the organization.

The intention was to mature the students with the following

- The students are responsible for the outcome of the project

- It is "mandatory" to be cooperative with other students with other (needed) skills than their own.

- It is needed to cooperate professional workshops

- No one to rescue you

- Their "job profile" is close to an engineering job

And of course by themselves find and learn new knowledge when it is needed. In many ways similar to a real paid work. In AAUSAT-II this was tried very radically. Faculty Management didn't talk at the weekly meetings - was only following the process.

In general this was functioning very good. The students was in control of the whole process - have been traveling around in the world - were handling and negotiating with supplier and so forth.

One problem did remain. When the real hard decisions has to be taken which can have radical effect on some of the subsystems or students and maybe even dump work already carried out. This turned out to be difficult for the students. So in these (rare) situations staff Management had to take affair. And students were gracefull for these interventions. For such an intervention to become accepted it needed to be followed up by waterproof arguments. Most of these arguments had often already been presented by the students in their management discussions.

This way of management from Faculty Staff still needs some refinement but it is the way to go. 


\section{IV.B. The Satellite from a Process Perspective}

A satellite is naturally organized in a number of subsystems. The main subsystems are: power supply, command and data handling, payload, attitude control, communication and ground station. To have a functional and efficient management each subsystem group appoints a delegate - a system engineer - which participates in the steering committee. A second seat in the committee is given to each group, occupied round-robin amongst the remaining group members. This ensures consistency and continuity in the steering committee and ensures that all students are included in the management tasks, while limiting the number of people present at meetings.

At AAU, this structure is mainly implemented in the first half of the project, since experience shows that the number of groups involved, and also the sizes of the groups, tend to decrease over the project period. This is due to the fact that tasks at the finalization of a satellite, i.e. implementation, integration, and testing, are not tasks which semester projects can be based on within the curriculum. Hence these tasks are typically done by students in their spare time, motivated by the prospect of launching the satellite into space. From an educator's point of view, this is an important benefit of PBL in space education, as the extra work put in by the students, also gives the students relevant hands-on experience, without compromising the scope of the curriculum's.

The steering committee ensures the maintenance of necessary system engineering documents, such as user and system requirement documents, time plans, milestones, etc. In the beginning of a satellite project, the main part of these tasks is handled by staff. As the project progresses, the maintenance responsibility of the documents are passed on to individual students in the steering committee. This is done to prevent work overload of the students at the beginning of the project, since project management is a comprehensive task, and the students have courses to follow, and sub-systems to design on top of this work.

\section{IV.C. Reaching a Flight Model}

The students as the final construction and launch of the flight model as the primary goal. A flight model has natural demands on components, design, testing before it can be accepted for a launch.In that perspective a 1-2 kg cubesat has many of the problems and solutions similar to professional satellites. The students has already got the first portions of real lessons learned in the space domain when they finalize their education.

It shall also not be forgotten that there exist a natural selection of students down the road when they experience that building a satellite is not just another student project.

It should also be noted that there exist a natural selection of students down the road when they experience that building a satellite is not just another student project. We believe that this is a successful way to prepare them and give them skills at the university for a career in the space domain.

We have the humble opinion that this is the best way to prepare them and give them skills at the University for a career in the space domain.

\section{IV.D. Foreign Students}

AAUSAT-II has gain interest on other Universities and foreign students has been participating in Aalborg for one or more semesters. One thing has become clear namely that the "System Engineering" oriented space engineer is very important. Visiting students from TU Delft, The Netherlands, has shown us qualities in this area that is difficult to obtain through our normal curriculum. These students had a lower level or basic engineering skills in the areas cited in section B in this paper. A high degree of symbiosis was reached which the project clearly did benefit on.

\section{The Curriculum}

At AAU there is no general space specialization. Instead it has been decided to extend the different educations and specialization with "space" curriculum. This has the advantage that students are integrated in our normal education and can "try" a space project for maybe one semester or continue for several semesters. In the coming AAUSAT3 "System Engineering" will be a common learning activity for all students due to the lessons learned. 


\section{Conclusion}

Studentspace at Aalborg University has proved that it is possible to educate space engineers of high quality within a normal engineering curriculum. What is needed is a skilled Faculty Staff with the necessary space skills and a educational systems which opens for multi semesters projects.

The space initiative as well the normal curriculum educations benefits from our way of an add-on. The PBL learning principle gives the students skills at an early stage in their education to produce high quality items for spacecrafts and other uses. In AAUSAT-II is components and subsystems which design has been started up by students at their fourth semester.

\section{References}

${ }^{1}$ AAU, The Aalborg PBL Mode, Aalborg University Press, 2004.

${ }^{2}$ Fink, F. K., "Integration of Engineering Practice into Curriculum 25 Years of Experience with Problem Based Learning," Proceedings of IEEE Frontiers in Education Conference, IEEE, Wahington, DC, 1999.

${ }^{3}$ et al, K., The Aalborg Experiment Project innovation in university education, Aalborg University Press, 1994.

${ }^{4}$ Bhanderi, Bisgaard, A. N., "A Danish Perspective on Problem Based Learning in Space Education," IEEE Aerospace and Electronics Systems Magazine, IEEE, Wahington, DC, 2006, pp. S19-S22. 